\title{
ALVM CORRÊA E SUAS MULHERES DESNUDAS
}

Thais Fernanda Martins Hayek

thaishayek@hotmail.com.br

Henrique Alvim Corrêa foi um dos artistas revolucionários da própria arte, quase perdido no anonimato, pelo descaso de seus conterrâneos até bem pouco tempo. De uma preocupação não somente estética, as obras que no presente texto serão tratadas, apresentam o retrato de uma época, anexa a uma "revelação" explícita de um simbolismo grotesco. Contudo faz-se necessário enfocar, à priori, o movimento Simbolista que terá influência direta nas criações do artista.

O Simbolismo ${ }^{1}$ foi movimento subjetivista, a priori surgido na França, em que ingressaram os artistas durante o período entre 1880 e 1910, uma reação à estética realista, naturalismo dos impressionistas e ao cientifícismo da classe burguesa (aparecendo como um resposta negativa aos valores existenciais e ideológicos da mesma) . Embebedando-se da não objetividade romântica, mas transformando-a em outro sentido ${ }^{2}$, revelando o caráter ilógico que marca o movimento.

Influenciados pela literatura simbolista ${ }^{3}$ de vasta divulgação com manifestos publicados nas revistas "La Revue Wagnérienne", "La vogue", "Revue Indepéndante" e "La Décadance". ${ }^{4}$ Segundo C. M. Bowra: "a herança do Simbolismo considera Baudelaire, Verlaine e Mallarmé, os vanguardistas deste movimento por suas inovacõoes técnicas na literatura". ${ }^{5}$ Em 1884, Verlaine publicou "Les poêtes mandits", que revelava ao mundo os mestres desta nova estética, entre eles Rimbaud, Tristan Corbiêre e Mallarmé.

Está neste período diante de uma nova afirmação, colocada por Baudelaire (1821-1867), de que não existe beleza absoluta e universal, mas sim uma diversidade estética, mediada pela cultura de cada povo. Sendo a beleza, uma sensibilidade estética peculiar, cada homem possui sua beleza pessoal. Contrapôs-se a idéia de que a arte deve servir a propósitos morais e sociais. Em um momento em que se exalta a racionalidade positivista, Baudelaire, em seu poema (Flores do mal), introduz uma nova linguagem; a "correspondência" que assume o moderno sentido lingüístico como instrumento expressivo totalizante.

\footnotetext{
1 À princípio chamado de "Decadentismo".

${ }^{2}$ Os românticos desnudavam somente a primeira camada dos sentimentos, já os simbolistas aprofundavam-se tanto nesta esfera do "eu" que adentraram, no que pode-se chamar de "inconsciente".

${ }^{3}$ Anunciado pela primeira vez em 1886, por Jean Moréas (1856-1910) em seu "Manifesto Simbolista", onde refuta as descrições objetivas, a técnica pela técnica, caracterizando a vanguarda como a busca da forma sensível e perceptível à alma humana.

${ }^{4}$ Revistas citadas em BALAKIAN, A. O Simbolismo. São Paulo: Perspectiva, 1985, pg: 11

${ }^{5}$ BOWRA, C. apud idem, pg: 12
} 
Essa nova poética de ruptura e passagem da existência positivista do real para $O$ valor da essência do ser. Sendo a palavra um instrumento simbólico a resultar em uma figuração da realidade, Baudelaire inspiraria poetas e artistas, com sua convicta teoria da correspondência: "todo universo visivel é apenas um armazém de imagens e signos, a que a imaginação atribuiu um lugar e um valor relativos: é uma espécie de alimento que a imaginação tem de digerir e transformar. ${ }^{6 "}$

Trata-se então de uma unificação das artes, sons transmutando-se em cores, cores metamorfoseando-se em palavras, palavras fluindo-se a corporalidade. O poeta Gustave Kahn, referir-se-ia a relação artista/obra, onde toda e qualquer tipo de manifestação artística partiria da subjetividade do artista para sua concretização, "objetivar o subjetivo". Para Mallarmé a poética simbolista se fundamentaria segundo Argan: "nas palavras que não valem pelo seu significado habitual ou lexical, e sim pelo que assumem no contexto, sendo geradoras de imagens".?

Os literatos simbolistas acreditavam que através do mundo onírico, proporcionado pelos sonhos, revelava-se o único nível vital da experiência profunda do artista. Desenvolveriam então teorias de arte, que serviriam para fundamentação ideológica para muitos artistas, em que a maior apreensão da realidade era capturada por meio da imaginação e da fantasia.

Os pintores estavam fortemente ligados a estes poetas e pode-se supor que teoria poética interiorizou-se dentro destes a priori, exteriorizando-se mais tarde em suas obras. Como grandes representantes desta arte simbolista apresentam-se, Paul Gauguin (1848-1903), Odilon Redon (1840-1916), Gustave Moreau (1826-1898), Alfred Kubin (1877-1959), Fernand Khnopff (18581921), Jean Delville (1867-1953), Lucien Lévy-Dhurmer (1865-1953), Gustav Klint (1862-1918) entre outros em grupo como "Rosa Cruz"8. Na escultura pode-se considerar Auguste Rodin (1840-1917) e Camile Claudel como representantes deste movimento.

Desta maneira, o Simbolismo na arte apresenta-se paralelamente ao Neo-Impressionismo ${ }^{9}$ e em oposição ao mesmo por seu caráter sentimental e espiritual apreendido na obra, para estes a arte é a representação exposta através dos símbolos, do que pode conceituar-se "além consciência". Esse mesmo Simbolismo é o reflexo do signo hermético, traduzido em metáforas de ritos estéticos. Conduzindo a busca do carregado, do melodrámatico, do feio, da caricatura, do pornográfico e do extravagante. Por que não pode esquecer-se que

\footnotetext{
${ }^{6}$ BAUDALAIRE, C. apud CHIPP, H. Teorias da arte moderna. São Paulo: Martins Fontes, 2000, pg: 46

${ }^{7}$ ARGAM, G. Arte Moderna. São Paulo: Comp. das Letras, 1992, pg;84

${ }^{8}$ Fundada em 1888 com Pelàdan como mentor espiritual, neste grupo haviam literatos e artistas, como Jean Delville e Felicién Rops.

9 Período de arte caracterizado pela "tecnização" da pintura
} 
os homens, pós Revolução Industrial já estão respondendo ao "mal estar" que o próprio mundo ofertou-lhes.

Dentre as correntes filosóficas que influenciaram o Simbolismo estão: o "intitucinismo" de Henry Bergson (1859-1941) ${ }^{10}$, teorias de Arthur Schopenhauer (1788-1860) ${ }^{11}$, teorias de Soren Kierkegaard (1813-1855) ${ }^{12}$, a filosofia oriental ${ }^{13}$ e as teorias de Nicolau Von Hartman ${ }^{14}$.

Já no Brasil, em 1888 começa a caminhar em direção ao Simbolismo e ao Decadentismo. O simbolismo tinha por conceito, não a representação das coisas em si, porém a sugestão de idéias e sentimentos por meio de um revestimento da linguagem direta com a utilização dos símbolos. Segundo Civita: "sua temática eram o ideal e o misticismo católico, as lendas mitos e alegorias, sonhos e paráfrases de grande poesia e qualquer tipo de lirismo, de preferência de caráter moralista. ${ }^{15}$ "

Dentro da literatura simbolista pode-se incluir o escritor e cronista Medeiros e Albuquerque, o poeta que inaugura o movimento no país Cruz e Souza (1861-1898), o crítico de arte Gonzaga Duque (1863-1911) e o escritor mineiro Alphonsus Guimarães (1870-1921). Dando maior valorização às cores, a importância do exercício da visualidade literária, integraria-se à cultura brasileira.

Nas artes plásticas, o movimento não teria tanta repercussão como na literatura, porém os poucos artistas seriam de essencial importância para a historicidade da arte brasileira. Com criações plásticas habitualmente representadas por alegorias, assim como figuras femininas dotadas de uma "áurea de misticismo”. Entre eles pode-se citar Heitor Malaguti, Eliseo Visconti (1866-1944), Hélios Sienlinger (1878-1965) e Henrique Alvim Corrêa (1876-1910), porém apesar de sua nacionalidade brasileira, desencadeará sua trajetória artística do outro lado do mundo, no coração da Europa.

Considerado como um movimento aristocrático, os artistas inseridos, tornaram motivo de férrea crítica, sucedida em desprezo. O público comparti-

\footnotetext{
${ }^{10}$ Tem como fundamentação a busca do "eu" supremo, que manifesta-se fora do controle da razão, partindo do princípio do abandono dos dogmas morais e religiosos.

${ }^{11}$ No livro "O Mundo Como Vontade e Representação", afirma que a existência depende da consciência em que aparece, assim o mundo não passa de uma representação, portanto não chega-se jamais à essência em si. Por outro lado, o espírito corresponde à vontade, pertencente a materialização do real. Sustentando que o real em si, não passariam de ilusórias aparências e a essência de todas as coisas está alheia à razão.

${ }^{12} \mathrm{~A}$ qual, o homem é uma síntese de infinito e finito; de temporal e eterno; de liberdade e de necessidade. Entende que qualquer opção do ser humano conduz ao desespero pela impossibilidade de uma fusão maniqueísta dentro de si mesmo.

13 Para os orientais, a salvação do homem está na renúncia dos bens materiais e mundanos, bem como a mortificação dos instintos humanos, para alcançar o nirvana.

${ }^{14}$ Criador da "teoria do inconsciente", entidade desconhecida, que aparece transmutada ao chegar no consciente. Sendo então um grande mistério, gerador do mal estar do homem, em virtude da impotência frente ao fenômeno enigmático do universo.
}

${ }^{15}$ CIVITA, V. Arte no Brasil. São Paulo: Abril, 1979, pg: 564 
lhou desta mesma opinião, considerando-a pretensiosa e complexa demais. Somente após o movimento Modernista, alguns destes poetas e artistas serão valorizados, influenciando escritores como Cecília Meireles, Vinícius de Moraes, Manuel Bandeira e Mário Quintana .

Henrique Alvim Corrêa, nascia no Rio de Janeiro, em 1876, onde moraria até 1892, quando mudaria para a Europa com sua família, morando em Lisboa, Paris e Bruxelas (onde moraria até o final de sua vida). Foi até bem pouco tempo um "estrangeiro em sua terra", sendo totalmente desconhecido ${ }^{16}$. Devido a invasão da Bélgica por ocasião da Primeira Guerra e ao descaso brasileiro ao não acolher suas obras em lugar apropriado. Descoberto por José Roberto Teixeira Leite, na década de 60, valorizando-na primordialmente por, seu contexto de época intrínseco em sua obra.

Em 1884 freqüenta o atêlier de Eduard Détaille (1848-1912) e em 1887 freqüenta o atêlier de Jean Brunet. Em 1904 especializa-se em gravuras, quando também executa algumas peças teatrais. Em um casamento alquímico entre a produção plástica e coerência interna, Alvim mostra-se um intelectual pertinente e um crítico de arte no mínimo instigante.

Em 1905 ilustra a edição belga de a "Guerra dos mundos" de H.G. Wells, utilizando-se do imaginário fantástico. As obras evocadas remetem a Bosch e a Brueghel, adequando as cenas de uma guerra entre marcianos e terrestres. A obra de Wells alerta sobre os perigos do novo cientificismo análoga a uma sátira social, romance de ficção científica onde também trata a temática da crueldade implícita no colonialismo. Os marcianos de Wells representam a alienação do colonialismo europeu, teorizando a visão racista das pessoas que moram nestes países colonizados.

Escreve peças teatrais, onde ressalta a modernidade e suas inquietações sociais, bem como visível em sua linguagem plástica. Sua criação não limita-se nestas obras, dando vida a um mundo erótico, bizarro, violento, pervertido e caótico, que também se faz presente em outras obras Simbolistas.

À priori, sua principal orientação artística era a pintura militar, em grande voga na França após a derrota da Prússia. Mais tarde Alvim evoluiria para temas mais livres e pessoais. Sua produção consiste em cerca de oitenta pinturas e trezentos desenhos (divididos em temas militares, nus, paisagens cenas de Boulevard, estudos de costumes e desenhos espontâneos). Segundo Civita, "Seu grande tema porém é a mulher".17

\footnotetext{
${ }_{16}$ Maria Bardi organizou a primeira exposição póstuma de Alvim Corrêa em 1972, no Museu de arte de São Paulo

${ }^{17}$ CIVITTA, V. Arte no Brasil, SP. Abril 1975, pg: 593
} 
Alvim Corrêa retrata em seus nus, os quais assina com o pseudônimo de H. Lemort ${ }^{18}$, um simbolismo "diabólico", figuras femininas em alegorias desumanas, quando descobre que sua melancolia se aparentava com o ácido sarcasmo de Rops, veiado de erotismo frustro, com o humor denso e imaginoso, a veia lírica e desencantada de Redon. Empregando neste imaginário uma forma de pensamento ocultista, propondo uma nova releitura do mito e dos mistérios, em busca de uma hermenêutica mais concisa com as próprias aspirações de sua época.

$\mathrm{Na}$ figura 1, ao primeiro plano vê-se uma mulher nua. Pregados em uma cruz, os pés estão juntos, um sobreposto ao outro. As mãos também pregadas, estão fechadas, expressando força (por seu caráter contraído) e dor. Os cabelos compridos escondem seu rosto, o seio direito e parte do seio esquerdo. Na parte horizontal da cruz, está o inscrito "Vae Victis". O plano de fundo é difuso contrastando com as firmes linhas do desenho da mulher e da cruz. $\mathrm{O}$ preto é utilizado como cor e não mais como contorno e em um degrade abrupto o branco vai fazendo-se presente, parecendo delimitar dois muros simétricos, mas quase abstratos.

A obra tem uma simbologia "herege", porque inverte a sexualidade do sagrado no mundo cristão. Porém deve-se considerar o fato que algumas sociedades ocultas já tratavam desta temática. É o caso londrino da "Sociedade Hermética" (1883) de Anna Kingsford e Edward Maitland" ${ }^{19}$, sociedade está "ligada à criagão de uma teologia feminina do Espirito Santo. ${ }^{20}$ "Será que está-se diante do final dos tempos?

O inscrito exalta as posturas antigas de sacrifício, a virgem que é entregue a um deus, como na história de Psique ${ }^{21}$, a sensualidade também é um reflexo de seu tempo como pode ser analisado na obra do artista belga Khnopff, que provavelmente o tenha conhecido. A figura 2 também tem a mesma relação intrínseca ao ocultismo, considerando ainda os elementos fantásticos que esta apresenta, de um grotesco "surreal" o peso da imagem contrapõe-se, sendo a mulher a leveza em equilíbrio ao ser que em baixo dela transmuta-se em uma expressão de horror. Ambos os artistas expressam metáforas intimistas de um

\footnotetext{
${ }^{18}$ Ora estampa nas iniciais HL uma caveira, ora um sapato alto, ora outro objeto afim.

${ }^{19}$ SILVA, Eliana M.- O ocultismo no século XIX Campinas: IFCH/Unicamp, 2001.

${ }^{20}$ Idem pg: 49

${ }^{21}$ Psique era uma mulher tão bela, que os homens acabaram por abandonar os templos de Afrodite para contempla-la. Afrodite porém enciumada e nervosa, pediu a Eros que acertasse uma flecha em Psique, para que está se apaixonasse pelo homem mais feio e nojento da face da terra. Acontece que ao vê-la, Eros se encantou e foi acertado pela sua própria flecha. Nos mitos gregos quando um deus apaixona-se por uma mortal, esta não pode casar-se. E assim Psique viu que todos a contemplavam mais nenhum queria casar-se com ela. Seus pais preocupados, foram até o oráculo e este pediu que a mesma fosse entregue em forma de sacrifício a um monstro celeste... ... assim subia à montanha Psique.
} 
universo feminino, acentuando um maniqueísmo religioso paradoxal. E como diz Michelet:

“A natureza as fez feiticeiras. É o gênio próprio à mulher e seu temperamento. Ela nasceu Fada. Pela volta regular da exaltação, ela é Sibila. Pelo amor ela é Mágica. Pela fineza e sua malícia, ela é Feiticeira, e faz a sorte ou, pelo menos, adormece, engana os males. ${ }^{22 "}$

Mas a mulher crucificada de Alvim Corrêa, é uma mulher "moderna", portanto não há apenas uma ícone religioso posto em questão, há uma cortesã sendo crucificada por sua beleza e feminilidade, há uma ruptura dos valores morais que está se formando e há o anti-herói de que falava Baudelaire.

Como um pêndulo, suas obras são tangenciadas entre a vida e a morte. Seu vocabulário plástico insere uma série de símbolos, as vezes explícitos e as vezes implícitos em seu próprio significado. Entretanto não dispensa uma carga sobrecarregada de ironia e muitas vezes de crítica social, mostrando sempre o lado perverso da fantasia.

Alvim retrata em uma de suas obras mulheres que são muitos íntimas, convidando o próprio contemplador à “olhar". Pode-se, neste momento, fazer uma analogia com o "flaneur ${ }^{23}$ " de Baudelaire, ou mesmo onde escreve sobre o amor lésbico feminino (outro signo do heroísmo da modernidade), com nomes gregos- Delfina e Hipólita;

\footnotetext{
"Mas Hipólita após, tendo a cabeça ereta:

- Eu ingrata não sou e de ti não me afasto,

Minha Delfina, eu sofro e agora sou inquieta, como após um noturno e terrível repasto." ${ }^{24}$
}

É o tempo de um lesbianismo que começa a explicitar-se nas obras com um caráter totalmente novo, a "sensualidade marginal".

Assim uma vontade enorme de quebrar os paradigmas da arte, está notoriamente presente em suas obras, afinal é um artista de um tempo "Moderno". E a modernidade já sabe que são de rupturas que se sobressaem os homens. Alvim Corrêa, desta maneira, é um artista que perpassa as barreiras temporais, impávido da imortalidade de "seus brinquedos perversos".

\footnotetext{
${ }^{22}$ MICHELET,J. A feiticeira São Paulo: Círculo do Livro, 1974.

${ }^{23} \mathrm{O}$ "flaneur" tem o caráter prazeroso de observar, um ver intimista que se assemelha ao sonho.

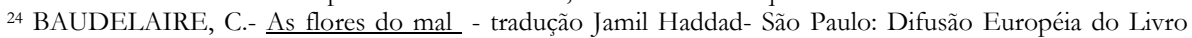
1964, pg: 269
} 


\section{Bibliografia}

\section{Catálogos de exposição:}

Alvim Corrêa. Pinturas e desenhos. Museu de Arte Moderna do Rio de Janeiro. Abril, 1973

CORRÊA, R. Henrique Alvim Corrêa. Ilustracões para a Guerra dos Mundos de H. G. Wells Rio de janeiro, Museu Nacional de Belas Artes, 1977.

EULALIO, A. O século XIX In: MARINO, J. org. Tradição e ruptura São Paulo, fundação Bienal de São Paulo, 1984.

\section{Dissertações:}

BARROS, Maria Stella Teixeira de Henrique Alvim Corrêa - correspondências e afinidades São Paulo, USP, 1996

\section{Livros:}

ARGAM, G. Arte Moderna. São Paulo: Comp. das Letras, 1992.

BALAKIAN, A. O Simbolismo. São Paulo: Perspectiva, 1985.

BAUDELAIRE, C.- As flores do mal - tradução Jamil Haddad- São Paulo: Difusão Européia do Livro 1964

BAUDELAIRE, C. A modernidade de Baudelaire/ apresentação Teixeira Coelho: tradução de Suely CassalRio de Janeiro: Paz e Terra 1988.

BENJAMIN, W. A modernidade e o moderno Rio de Janeiro: Tempo Universitário, 1975 .

CAVALCANTI, C. (coordenador) Dicionários dos artistas brasileiros. São Paulo: Ministério da Ed. e Cultura, 1969.

CHEVALIER, J. \& GHEERBRANT, A. Dicionário dos símbolos. Rio de Janeiro: José Olimpyo, 1982.

CIVITA, V. Arte no Brasil- vol. I. São Paulo: Abril, 1979.

CIVITA, V. Arte no Brasil- vol. II. São Paulo: Abril, 1979.

CHIPP, H. Teorias da arte moderna. São Paulo: Martins Fontes, 2000.

Dicionário da Artes Plásticas no Brasil Rio de Janeiro: Civilização brasileira, 1969.

JANSON, H. História da Arte. Lisboa: Ed. F.C.G., 1989.

KAYSER, W. O grotesco São Paulo: Perspectiva, 1986.

MICHELET, J. A Feiticeira. São Paulo: Círculo do livro, 1974.

MUSEU LASAR SEGAL A caricatura no Brasil. São Paulo: 1979

SPERBER,D. Simbolismo em geral São Paulo: Cutrix, 1974. 


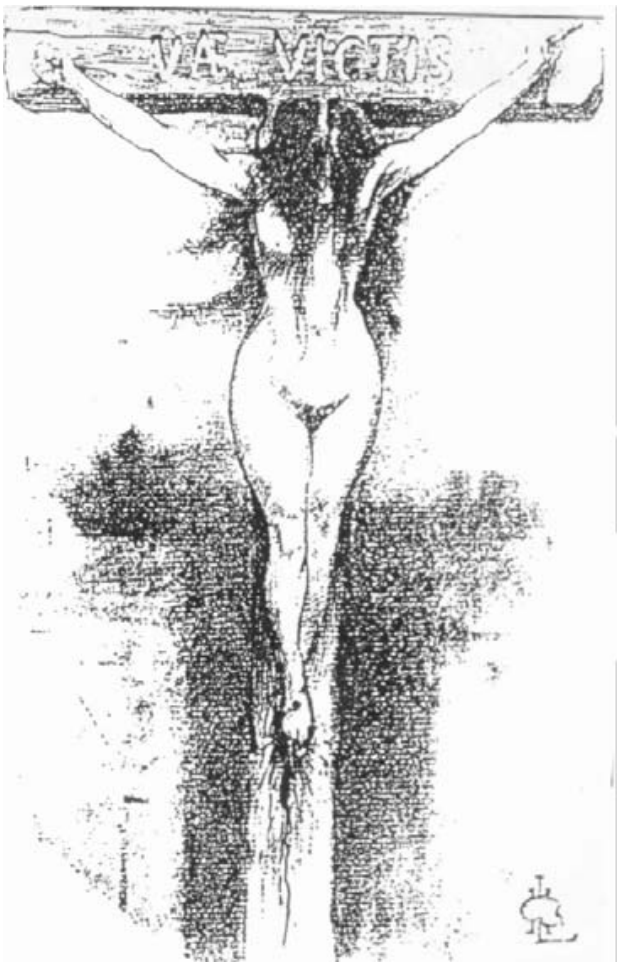

Fig. 1- ALVIM CORRÊE, Henrique

Vae Victis, s. data

Crayon e aquarela s. papel

$41 \times 28 \mathrm{~cm}$

Musées Royaux des Beaux-Arts, Bruxelas

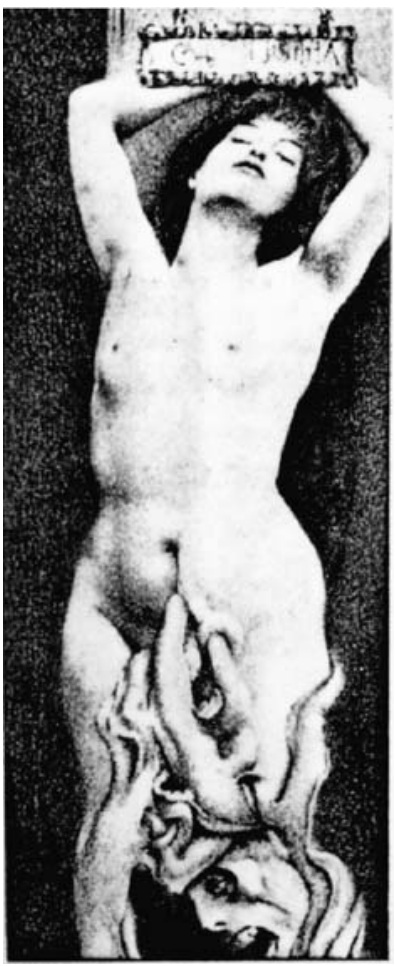

Fig. 2-KHNOPFF, Fernand Istar, 1888

Sanguínia s. papel $16,5 \times 7$

Col. Particular

Thais Fernanda Martins Hayek. Graduada pela Universidade Federal de Uberlândia- Bacharel em Educação Artística/Artes Plásticas. Mestrado em Estética e História da Arte- Programa Interunidades - Universidade Federal de São Paulo. (em curso). 